\title{
Article
}

Mycosphere

Doi 10.5943/mycosphere/7/6/12

Copyright (C) Guizhou Academy of Agricultural Sciences

\section{Biocontrol of Leucoagaricus gongylophorus of leaf-cutting ants with the mycoparasitic agent Trichoderma koningiopsis}

\author{
Castrillo ML ${ }^{1,2^{*}}$, Bich $\mathrm{GA}^{1,2^{*}}$, Zapata $\mathrm{PD}^{2}$ and Villalba $\mathbf{L L}^{2}$ \\ ${ }^{I}$ Microbiology and Immunology Laboratory. Misiones National University. 1375, Mariano Moreno Ave. 3300 (Zip \\ code). Posadas Misiones, Argentina. E-mail: mlc_827@hotmail.com. \\ ${ }^{2}$ Biotechnology Institute of Misiones "María Ebe Reca". 12 Road, Km 7,5. Postal Code 3300. Misiones, Argentina. \\ *These authors contributed equally to this work.
}

Castrillo ML, Bich GA, Zapata PD, Villalba LL 2016 - Biocontrol of Leucoagaricus gongylophorus of leaf-cutting ants with the mycoparasitic agent Trichoderma koningiopsis. Mycosphere 7(6), 810-819, Doi 10.5943/mycosphere/7/6/12

\begin{abstract}
Leaf-cutting ants are one of the main agricultural and agroforestry pests in the Neotropic region. The essential food source of these ants is Leucoagaricus gongylophorus. Therefore one of the main biocontrol agents under study are Trichoderma species, because of their biocontrol activity against a diverse range of fungi. Here, Trichoderma koningiopsis, isolated from a leafcutting ants nest was tested against three Leucoagaricus gongylophorus strains from leaf-cutting ants by dual culture technique under laboratory conditions. The molecular analysis of ITS sequence data showed three well-separated main clades in which the isolated Trichoderma strain was assembled as a sole subclade among $T$. koningiopsis strains. The tests also showed that $T$. koningiopsis strain inhibited the growth of all L. gongylophorus strains tested. The values of radial inhibition of L. gongylophorus ranged from $58 \%$ to $69 \%$ with an average mean value of $65 \%$. This is the first report on a strain of T. koningiopsis isolated from a naturally parasitized nest of leafcutting ants with biocontrol ability over L. gongylophorus tested in dual culturing method.
\end{abstract}

Key words - biological control - leaf-cutting ants - Leucoagaricus gongylophorus - Trichoderma koningiopsis.

\section{Introduction}

In the New World, leaf-cutting ants are dominant herbivores and major agricultural and agroforestry pests (Folgarait et al. 2011, Napal et al. 2015). Furthermore, the economic damage in the neotropic agricultural industry caused by Atta and Acromyrmex genera of ants is enormous and these ants are among the most serious agricultural pests of tropical and subtropical America (Silva et al. 2006, Della Lucia et al. 2014).

Ants of the Attini tribe live in obligate symbiosis with a basidiomycete fungus of the Agaricaceae family which is an essential food source for the larvae and queen (Fig. 1) (Fisher et al. 1994, Currie 2001, Miyashira et al. 2010). The fungal symbiont of the leaf-cutting ants is the basidiomycete Leucoagaricus gongylophorus (Fisher et al. 1994, Silva et al. 2006, Miyashira et al. 2010, Napal et al. 2015, Bich et al. 2016).

Despite their low specificity, high toxicity, adverse effects to the environment and development of resistant insect populations, chemical insecticides have been used traditionally for 


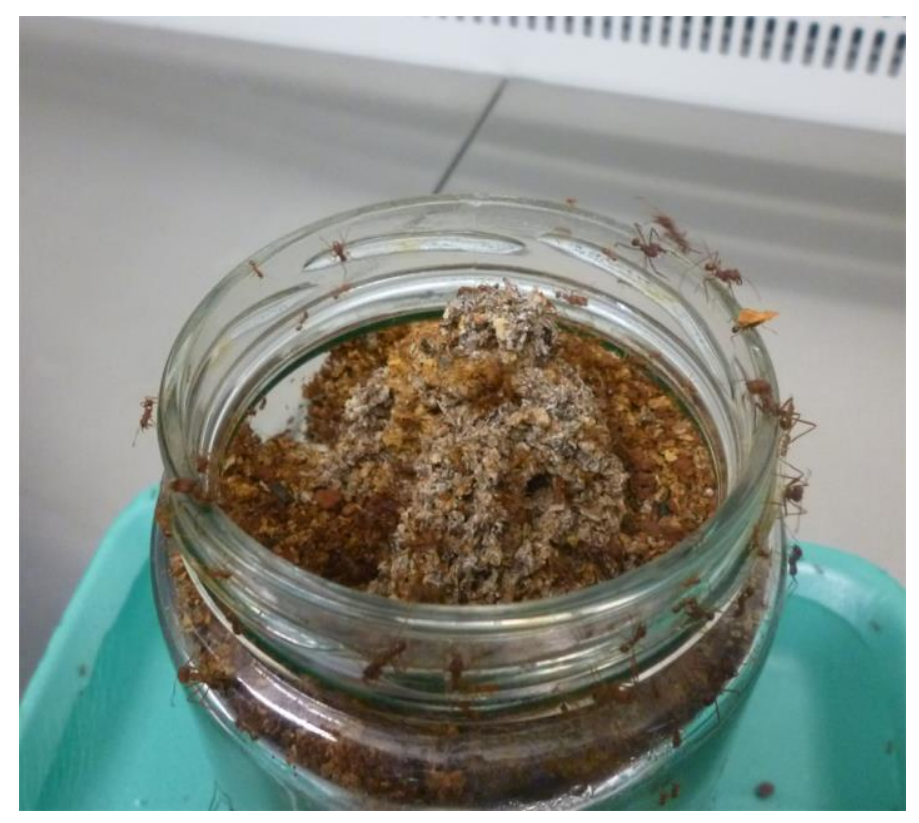

Fig. 1- Leucoagaricus gongylophorus grown in a fungal garden of leaf-cutting ants

leaf-cutting ants control (Lopez \& Orduz 2003). Consequently, there is need for new and alternative control methods that can provide more sustainable and efficient control of leaf-cutting ant colonies (Folgarait et al. 2011, Napal et al. 2015). Alternatives to chemical insecticides are being researched and developed (Lopez \& Orduz 2003, Folgarait 2013). Consequently application of chemical insecticides is being replaced or complemented by biocontrol agents because of the emergence of insecticide-resistant populations and public concerns regarding the health and environmental impacts of these chemicals.

During the last few decades, several potential biocontrol organisms have been isolated, characterized and commercialized, and thus, biocontrol of insects in forestry has received more attention (Shali et al. 2010, Folgarait et al. 2011). The genus Trichoderma was widely studied due to its rapid growth, capability of utilizing diverse substrates, and resistance to diverse chemicals (Kamala et al. 2015). Furthermore, Trichoderma species have been investigated as biological control agents (BCAs) and growth promoter agents of many crops (Hermosa et al. 2000, Howell 2003, Kubicek et al. 2008, Savazzini et al. 2009), but it is only recently that these strains have become commercially available. The competition with pathogens, parasitism and the production of antifungal compounds are the most important mechanisms in biocontrol activity of Trichoderma (Savazzini et al. 2009, Yao et al. 2016). Usually Trichoderma strains have adaptation capacities in different types of soil and persist at detectable levels for months.

Strains of Trichoderma spp. can vary in their biocontrol activity from pathogen to pathogen, so each Trichoderma strain must be assayed against the target fungal species (Rojan et al. 2010). The knowledge concerning the behavior of these fungi as antagonists is essential for their effective usage in agronomy and forestry since they act against target organisms in different ways. The commercial usage of Trichoderma as BCAs must be then preceded by precise identification, adequate formulation and studies about the synergistic effects of the biocontrol mechanisms (Hermosa et al. 2000). Accurate species identification of Trichoderma based on morphology is very difficult and even ambiguous because of similarity of morphological characters and increasing numbers of morphologically cryptic species (Druzhinina et al. 2005, Samuels et al. 2010). The increase in the number of isolates, high phenotypic variability and similarity with Hypocrea and Gliocladium can complicate the identification of Trichoderma spp. through classic taxonomy (Hernández et al. 2015). These features have already led to misidentifications (Kubicek et al. 2008).

There is strong evidence that molecular methods and identification tools based on sequence analysis of genes enable the identification of every Trichoderma isolate (Druzhinina et al. 2005, 
Kubicek et al. 2008). To date there is limited knowledge about molecular identification and evaluation as BCA of newly isolated Trichoderma strains from Argentina. There are few studies of dual culture methods of Trichoderma against Leucoagaricus gongylophorus strains from leafcutting ants.

The development of new biocontrol products against plant pests requires screening of candidate antagonists which have to fulfill many requirements to be commercially successful (Kohl et al. 2011). In the present study, molecular identification and potential use of a newly isolated Trichoderma koningiopsis as BCA was tested in-vitro for the biocontrol of Leucoagaricus gongylophorus strains from leaf-cutting ant.

\section{Materials \& Methods}

\section{Microorganisms used}

Leaf-cutting ant nests were sampled from Misiones Province (Argentina). The nests were mechanically opened and a portion of the inner fungal garden was placed in a sterile plastic plate and taken to the laboratory. A small portion of a fungal garden naturally parasitized by Trichoderma was subcultured in 3.9\% Potato Dextrose Agar (PDA) (Britania). The agar plates were incubated for 3 to 5 days in dark at $28 \pm 1{ }^{\circ} \mathrm{C}$ to enable the development of Trichoderma. Only one Trichoderma strain was isolated from the inner fungal garden. The fungus was first isolated by subculturing in PDA medium and then stored at $4{ }^{\circ} \mathrm{C}$ in the biotechnology strain culture collection of the Misiones Biotechnology Institute (INBIOMIS - Misiones National University). Conidiophore structures and morphology were examined using a trinocular microscope (Barnett \& Hunter, 1998, Samuels et al. 2006). Three strains of Leucoagaricus gongylophorus, previously isolated by our group were tested; two of these strains (HEP4 and HEP12) were isolated from Acromyrmex pubescens nests and one strain (HEP20) was isolated from Atta laevigata nest. From each leaf-cutting ant nest small portions of fungal garden were subcultured in 3.9\% PDA (Britania). The agar plates were incubated as cited previously. The HEP4, HEP12 and HEP20 $L$. gongylophorus strains were also stored at $4{ }^{\circ} \mathrm{C}$ in the biotechnology strain culture collection of the Misiones Biotechnology Institute.

\section{Fungal molecular identification}

Mycelia for DNA extraction were grown in liquid cultures at $28 \pm 1 \mathrm{C}$ in malt extract broth (MEB) for 3-5 days in the dark. Hyphae were collected on filter paper in a Buchner funnel, washed with distilled water and the extraction of genomic DNA was performed with minor modification as described by Hermosa et al. (2000). DNA was resuspended in $30 \mu 1$ of sterile distilled free of DNAse water $\left(\right.$ Biopak $\left.^{\circledR}\right)$. DNA extracted was further examined by electrophoresis in $1 \% \mathrm{w} / \mathrm{v}$ agarose gels (InBio, Argentina) and stained with Gel Red Solution (Biotium, 10000X). The final DNA elution was then quantified spectrophotometrically. Primers ITS1 and ITS4 were used to amplify a fragment of rDNA including ITS1 and ITS2 regions and the 5.8S and partial 18S and 28S rDNA genes (White et al. 1990). PCR amplifications were performed in a total volume of $20 \mu 1$ with approximately $10 \mu \mathrm{g}$ of genomic DNA using 1 unit of Taq DNA polymerase (InBio, Argentina) per reaction. Each $20-\mu 1$ reaction consisted of $1 \mathrm{X}$ buffer (provided by the manufacturer), $2.5 \mathrm{mM} \mathrm{MgCl} 2$ (supplied with the enzyme), 10 pmol of each of the two primer solutions, $200 \mu \mathrm{M}$ of nucleotide mix (InBio, Argentina) and free of DNAse water to complete de volume. Reactions were amplified through an initial denaturation at $94^{\circ} \mathrm{C}$ for $3 \mathrm{~min}$, followed by 35 cycles at the following parameters: 40 seconds at $94^{\circ} \mathrm{C}, 40$ seconds at $52^{\circ} \mathrm{C}$, and 40 seconds at $72^{\circ} \mathrm{C}$, followed by a final extension step at $72^{\circ} \mathrm{C}$ for ten minutes. A negative control with all the reaction mixtures except the DNA template was included with each set of the PCR amplification reactions. Amplifications were confirmed by standard gel electrophoresis, using $2 \% \mathrm{w} / \mathrm{v}$ agarose gels (InBio, Argentina) in 0.5X TBE Buffer and stained with Gel Red Solution (Biotium, 10000X). After amplification the amplicons were sent to Macrogen Korea to sequence in both directions to corroborate the PCR product. 
The ITS1-5.8S-ITS2 sequence generated in this study was deposited in GenBank (National Center for Biotechnology Information) under accession number KU712257. The ITS sequence of the fungal strain was compared with sequences in GenBank and TrichoKey (Druzhinina et al. 2005). Moreover, to identify the isolated Trichoderma, 21 accessions of the ITS1-5.8S-ITS2 sequences were selected and retrieved from the GenBank data base representing species within the Trichoderma genus. Nucleotide sequence retrieved in this study consisted of about $600 \mathrm{bp}$ which correspond to the ITS1-5.8S-ITS2 and partial $18 \mathrm{~S}$ and $28 \mathrm{~S}$ regions. A sequence from the Ascomycote Beauveria bassiana (KJ409587) was used as an outgroup to demonstrate the situation of the root. DNA sequences were aligned using the Clustal W program. The phylogenetic methods were based on a distance-based method (Neighbor joining - NJ) and a cladistic method (Maximum Likelihood - ML). Support for specific clades represented in the tree was estimated by bootstrap analysis of 5,000 replications. Nucleotide divergences were estimated using Kimura's twoparameter method. The MEGA 6.0 package was used for the analyses. Phylogenetic data have been submitted to TreeBase with submission number S18932.

\section{Biocontrol in-vitro antagonism technique}

In-vitro antifungal activity of $T$. koningiopsis against symbiont $L$. gongylophorus strains was tested on a modified dual culturing method (Hermosa et al. 2000, Rojan et al. 2010, Hernández et al. 2015). Agar plugs ( $5 \mathrm{~mm}$ in diameter) cut from the growing edge of ant fungal symbiont strains (one L. gongylophorus at a time) and from Trichoderma were placed $3 \mathrm{~cm}$ from each other and incubated at $28 \pm 1{ }^{\circ} \mathrm{C}$. Because L. gongylophorus strains have a very slow radial growth (about $0.5 \mathrm{~cm} /$ week) related to Trichoderma, plates with $L$. gongylophorus strains were previously incubated producing a fungal colony of approximately $1 \mathrm{~cm}$ in diameter. The radial growth of all fungi was measured. Growth parameters in all confrontation cultures were daily assessed during ten days after inoculation. Morphological characteristics of the sporulation on the symbiont colony were recorded. Inhibition of radial growth of fungi and Trichoderma growth over fungal symbiont were measured and compared to controls. Percent inhibition of mycelial growth of Leucoagaricus over control was determined following the formula given by Aquino et al. (2008) where the percentage inhibition of radial growth $(\mathrm{PIRG})=(\mathrm{a}-\mathrm{b}) / \mathrm{a} * 100$, where $\mathrm{a}=$ the radius of the $L$. gongylophorus colony without the biocontrol agent and $\mathrm{b}=$ radius of L. gongylophorus colony in the presence of T. koningiopsis.

\section{Statistical analyses}

All antagonisms experiments were conducted in three replicates and data presented were average of replicates along with the standard deviation. Database was subjected to an analysis of variance (ANOVA) (STATGRAPHICS Centurion XV, StatPoint, Inc., USA) and results which have $p<0.05$ were considered as significant. Differences among the means were evaluated using Fisher's least significant difference (LSD) procedure.

\section{Results}

\section{Isolation and morphological characterization}

Fifteen fungal gardens of leaf-cutting ant nests from Misiones (Argentina) were sampled. One Trichoderma koningiopsis strain was isolated from the inner fungal garden from an Acromyrmex pubescens nest. The colony grown on PDA in darkness produced dense white mycelium with some green areas. There was also aerial mycelium with dispersed conidia. No distinctive pigment diffused to the agar was observed. Microscopically, the phialides were straight $(7 \mu \mathrm{m} \times 2.6 \mu \mathrm{m})$ with ellipsoidal conidia $(4 \mu \mathrm{m} \times 3.0 \mu \mathrm{m})$. The morphology of the colony and conidiophore structures allowed us to classify the fungal isolate as belonging to the Trichoderma genus. 


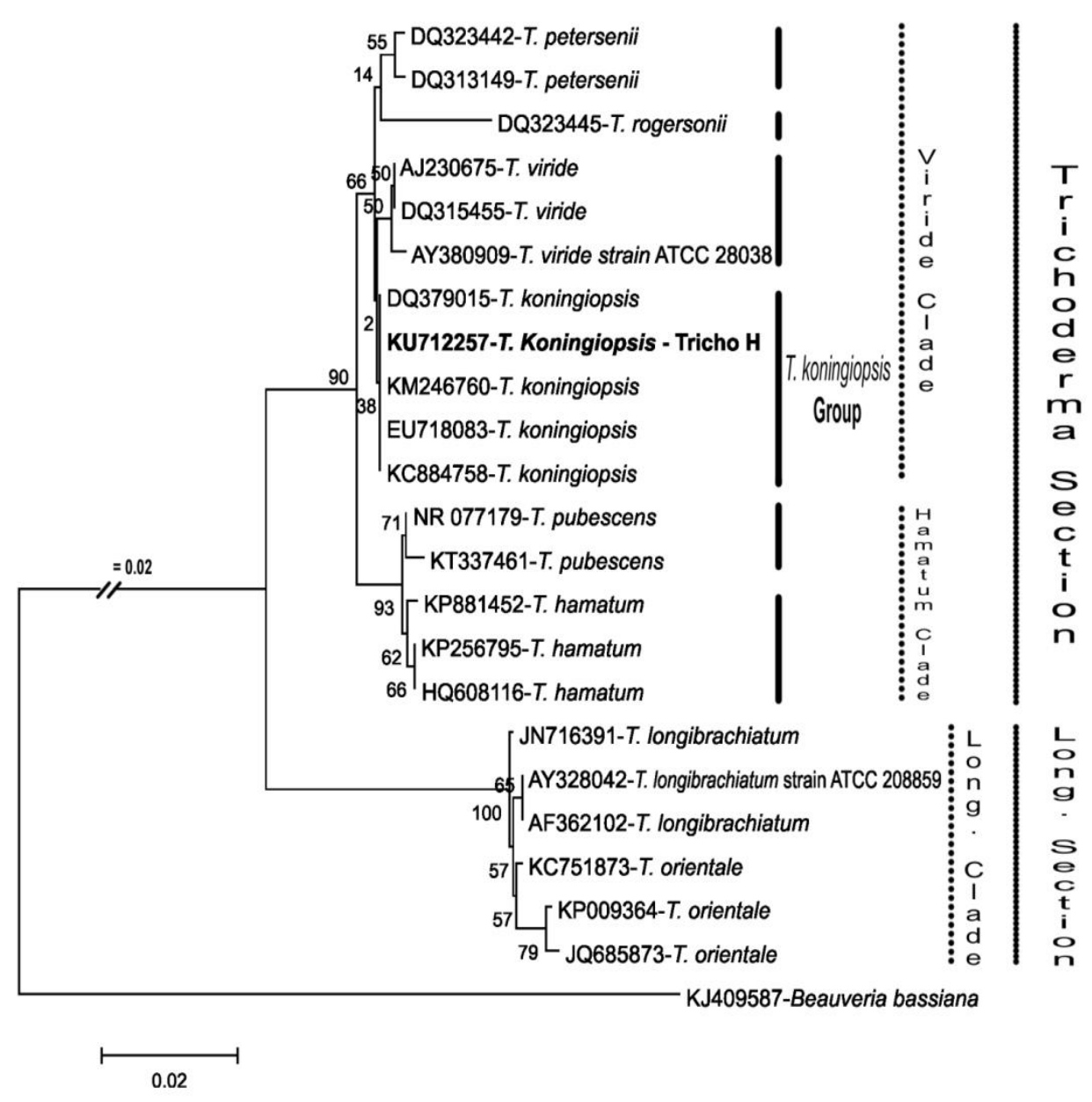

Fig. 2 - Phylogenetic relationships among Trichoderma isolates inferred from nucleotide sequences of the internal transcribed spacers and $18 \mathrm{~S}, 5.8 \mathrm{~S}$ and $28 \mathrm{~S}$ RNA genes. The sequence of the $T$. koningiopsis isolated from leaf-cutting ant nest is in bold. A sequence of B. bassiana was used as outgroup. The numbers next to the branches indicate the percentage in which a given branch was supported in 5,000 bootstrap replications. Long. = abbreviation of Longibrachiatum.

\section{Molecular characterization and phylogenetic analysis}

For molecular identification the genomic DNA was extracted and amplified using the ITS 1 and ITS 4 primers of the rDNA region. The ITS sequence obtained had $591 \mathrm{bp}$ after sequencing and contig construction. The rDNA sequence was deposited in GenBank under accession number KU712257.

The phylogenetic tree obtained by sequence analysis of ITS region of the Trichoderma strains selected is represented in Fig. 2. NJ and ML analyses of the selected ITS sequences of Trichoderma strains demonstrated a total of three distinct clades and all the clades were phylogenetically distinct from each other. Clade 1 comprised $T$. koningiopsis, T. viride, T. rogersonii and $T$. petersenii strains representing the Viride Clade which was supported by a bootstrap value of $66 \%$. Furthermore, based on the ITS region, the Viride Clade included one $T$. koningiopsis group which clustered all T. koningiopsis sequences (including our Trichoderma strain isolated from leaf-cutting ant nest). Clade 2 (Hamatum Clade) clustered strains of T. pubescens along with $T$. hamatum strains were supported by a bootstrap value of $93 \%$, whereas Clade 3 (Longibrachiatum) comprised $T$. longibrachiatum and T. orientale strains with a bootstrap value of $100 \%$. In addition, Viride and Hamatum Clades clearly showed a separation of the Longibrachiatum Clade as they belong to different Section in Trichoderma Phylogeny (Trichoderma and Longibrachiatum Sections respectively). 

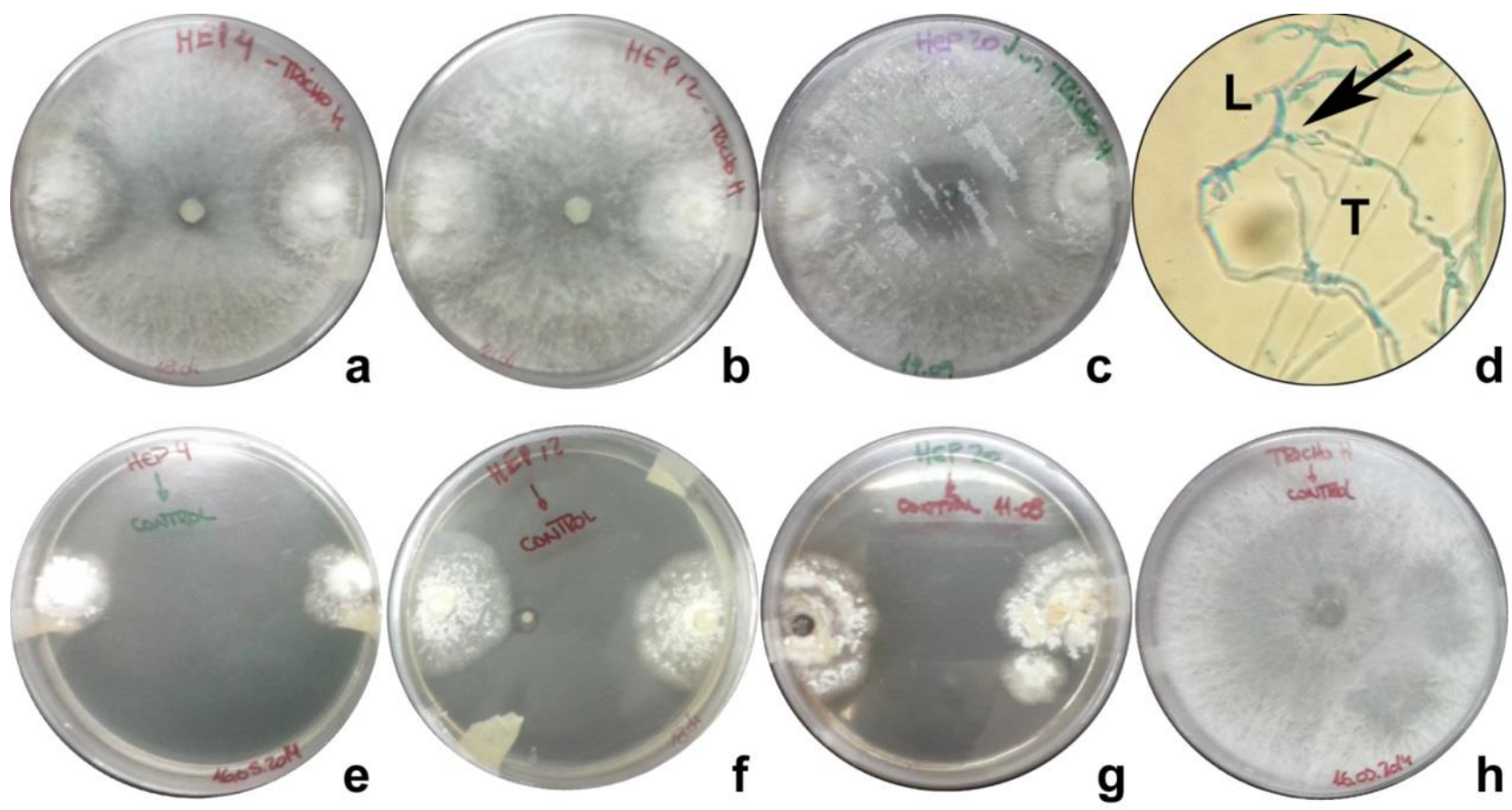

Fig. 3 - Plate assay for antagonistic activity of T. koningiopsis against L. gongylophorus strains. a. to c: Trichoderma growth and inhibition of Leucoagaricus growth after 10 days. d. Microscopic photograph of Trichoderma (T) and Leucoagaricus (L) strains contact zone (arrow marks attack zone) (400x). e-g. Leucoagaricus control growth. h. Trichoderma control growth.

Table 1 PIRG rate of Leucoagaricus gongylophorus by Trichoderma koningiopsis.

\begin{tabular}{|c|c|}
\hline L. gongylophorus & PIRG $\% \pm \mathrm{SD}$ (mean) \\
\hline HEP 4 & $67.37^{\mathrm{a}} \pm 8.92$ \\
\hline HEP 12 & $69.78^{a} \pm 3.08$ \\
\hline HEP 20 & $58.03^{\mathrm{a}} \pm 10.01$ \\
\hline & $65.06 \%$ \\
\hline
\end{tabular}

Values with same letter denote that the values are not significantly different.

\section{Biocontrol assay}

The fungal isolate identified as $T$. koningiopsis was evaluated against three $L$. gongylophorus strains from leaf-cutting ant nests. The parameters with reference to inhibition growth were recorded and evaluated. All L. gongylophorus strains had a slower growth rate in agar plates than T. koningiopsis. It was observed that contact between fungal colonies occurred after 72 hours post inoculation in all treatments.

The T. koningiopsis isolate grew almost completely over all L. gongylophorus colonies after the observation period (10 days) (Fig. 3). No further growths of L. gongylophorus were observed in Trichoderma control plates. L. gongylophorus HEP12 was found to be the most susceptible to $T$. koningiopsis presence and revealed the highest percent of inhibition of mycelia growth of more than $69 \%$. In contrast, HEP20 was the most resistant and revealed the lowest percent inhibition of mycelial growth (58\%), although there were not significant differences among treatments (Table.1). The mean PIRG value of T. koningiopsis against all the tested L. gongylophorus was $65.06 \%$ when compared to control plates. On the basis of dual culture experiment the antagonist effect of $T$. koningiopsis was significant against all the tested $L$. gongylophorus strains. All three $L$. gongylophorus grew fully on control plates after prolonged incubation. 


\section{Discussion}

Howell (2003) suggested that the best method for obtaining a potential biocontrol agent might be one where the candidate Trichoderma species is isolated from areas of soil where it is expected to function in biocontrol, and where this Trichoderma is growing under similar conditions of temperature, moisture, and nutrient availability to those found in nature. So the isolation of the Trichoderma strain obtained from the inner fungal garden of leaf-cutting ant can favor its biocontrol efficacy.

The morphological characters used to identified the Trichoderma koningiopsis strain are in agreement with Samuels et al. (2006) who described the morphological characters of the sexual and anamorph state of this genus and particularly this species (but we did not observed the development of chlamydospores in the T. koningiopsis isolate evaluated).

Related to the phylogenetic tree obtained by sequence analysis of ITS region of the Trichoderma strains selected, our results were in agreement with previous investigations on topology of Trichoderma Phylogeny (Hermosa et al. 2000). Furthermore Kuhls et al. (1997) employing ITS sequences for Phylogenetic analyses discriminated clades of Trichoderma section from clades of Longibrachiatum section.

In the biocontrol assays the T. koningiopsis strain showed percentage inhibition of radial growth between 58\% and 69\%. Silva et al. (2006) found $75 \%$ of inhibition in their dual plate growth evaluation of one strain of T. harzianum against one strain of L. gongylophorus isolated from Atta sexdens nest. Lopez \& Orduz (2003) in their study of entomopathogenic and mycoparasitic fungi (Metarhizium anisopliae and T. viride, respectively) evaluated the biological control of $A$. cephalotes nests under laboratory and field conditions. These authors reported that these fungi were more effective in controlling the nests than chemical insecticide, providing evidence that the biological control of leaf-cutting ants using fungi is a viable control alternative.

On the basis of dual culture experiment the antagonist effect of $T$. koningiopsis was significant against all the tested L. gongylophorus. All three L. gongylophorus grew fully on control plates after prolonged incubation. In a similar study Susanto et al. (2005) also documented that among other genera (Trichoderma spp., Gliocladium sp., Bacillus spp. Pseudomonas spp.) a strain of T. harzianum gave the highest inhibition capacity in dual culture analysis against the Basidiomycete Ganoderma boninense.

As seen in microscopic photographs hyphae of Trichoderma koningiopsis presented mycoparasitic phenomena like competition for space and growing along and coiling around the $L$. gongylophorus hyphae (Fig. 3.d). Howell (2003) and Steyaert et al. (2003) cited that one of the most outstanding characteristic of members of the genus Trichoderma is their ability to parasitize other fungi through mechanisms including coiling around pathogen hyphae, penetration, and subsequent dissolution of the host cytoplasm. Hernández et al. (2015) also found high levels of hyperparasitism with $T$. koningiopsis hyphae rolled into Macrophomina phaseolina hyphae, demonstrating a strong potential for use as a control agent.

Antibiotic production, mycoparasitism, production of cell wall-degrading enzymes and competition for nutrients or space (or a combination of these antagonistic activities) are considered as the main actions involved in biocontrol of pathogens (Zeilinger \& Omann 2007, Vinale et al. 2008, Saba et al. 2012, Yao et al. 2016). During direct contact, lectins in the host's cell wall can induce coiling of the Trichoderma around the host hyphae and mycoparasite can produce appressorium-like structures to destroy the pathogen (Zeilinger \& Omann 2007).

In terms of sporulation and aggressiveness of the BCAs, Hermosa et al. (2000) suggested that these two mechanisms depend on the kind of fungal target. Consequently the study of a native Trichoderma strain against native L. gongylophorus strains was required in the search of effective BCA against leaf-cutting ants. However it is always difficult to extrapolate the biocontrol activity of a given strain from the laboratory to natural environments.

Due to the widely use of dual culture method in antagonistic studies, the present investigation was based on this technique to test one $T$. koningiopsis strain against three fungal 
strains used as food source for leaf cutting ants. Treatments with T. koningiopsis presented reduced mycelial growth of fungal symbiont of leaf-cutting ants.

According to Della Lucía et al. (2014) fungus contamination is an interesting control possibility, particularly in small and shallow ant colonies. Based upon these data, biocontrol of leafcutting ants with Trichoderma may reduce the use of chemical pesticides. To prove the antagonistic action of the selected strain of Trichoderma against the tested L. gongylophorus these promising results could be tested in field bioassays as a biocontrol agent of leaf-cuttings ants.

\section{Acknowledgements}

The authors are sincerely thankful to the National Scientific and Technical Research Council - (CONICET) Argentina for doctoral fellowship of Castrillo and Bich; and the Comité Ejecutivo de Desarrollo e Innovación Tecnológica Misiones (CEDIT) for partial fellowship of Bich.

\section{References}

Aquino JG, Vázquez LM, Reyes BG. 2008 - Biocontrol in-vitro e in-vivo de Fusarium oxysporum Schlecht.f. sp. Dianthi (Prill. y Delacr.) Snyder y Hans con hongos antagonistas nativos de la zona florícola de Villa Guerrero. Rev Mexicana Fitopatología 26, 127-137.

Barnett IL, Hunter BB. 1998 - Illustrated Genera of Imperfect Fungi. Fourth Edition. Macmillan Publishing Company, New York.

Bich GA, Castrillo ML, Villalba LL, Zapata, PD. 2016 - Isolation of the symbiotic fungus of Acromyrmex pubescens and phylogeny of Leucoagaricus gongylophorus from leaf-cutting ants. Saudi Journal of Biological Sciences In Press, Corrected Proof, Available online 19 May 2016.

Currie CR. 2001 - Community of ants, fungi and bacteria: A multilateral approach to studying symbiosis. Annual Review of Microbiology 55, 357-380.

Della Lucia TM, Gandra LC, Guedes RN. 2014 - Managing leaf-cutting ants: peculiarities, trends and challenges. Pest Management Sciences 70, 14-23.

Druzhinina IS, Kopchinskiy AG, Komonm BJ, Szakacs G, Kubicek CP. 2005 - An oligonucleotide barcode for species identification in Trichoderma and Hypocrea. Fungal Genetics Biology 42, 813-828. doi:10.1016/j.fgb.2005.06.007.

Fisher PJ, Stradling DJ, Pegler DN. 1994 - Leucoagaricus basidiomata from a live nest of the leafcutting ant Atta cephalotes. Mycology Research 98, 884-888.

Folgarait P, Gorosito N, Poulsen M, Currie C. 2011 - Preliminary In Vitro Insights into the Use of Natural Fungal Pathogens of Leaf-cutting Ants as Biocontrol Agents. Current Microbiology Journal 63, 250-258. DOI 10.1007/s00284-011-9944-y.

Folgarait P. 2013 - Leaf-Cutter Ant Parasitoids: Current Knowledge. Psyche, Article ID 539780. doi:10.1155/2013/539780.

Hermosa MR, Grondona I, Iturriaga IA, Díaz JM, Castro C, Monte E, García I. 2000 - Molecular Characterization and Identification of Biocontrol Isolates of Trichoderma spp. Applied Environmental Microbiology 66, 1890-1898.

Hernández JL, Sánchez MI, González JM, DiCarlo J, García JG, Rene H. 2015 - Antibiosis of Trichoderma spp strains native to northeastern Mexico against the pathogenic fungus Macrophomina phaseolina. Brazilian Journal of Microbiology 46, 1093-1101. DOI: http://dx.doi.org/10.1590/S1517-838246420120177.

Howell CR. 2003 - Mechanisms employed by Trichoderma species in the biological control of plant diseases: the history and evolution of current concepts. Plant Disease 87, 4-10.

Kamala T, Indira S, Chandradev K, Kennedy K. 2015 - Phylogeny and Taxonomical Investigation of Trichoderma spp. from Indian Region of Indo-Burma Biodiversity Hot Spot Region with Special Reference to Manipur. BioMed Research International, Article ID 285261. Doi:10.1155/2015/285261. 
Köhl J, Postma J, Nicot P, Ruocco M, Blum B. 2011 - Stepwise screening of microorganisms for commercial use in biological control of plant-pathogenic fungi and bacteria. Biological Control 57, 1-12. doi:10.1016/j.biocontrol.2010.12.004.

Kubicek CP, Komon M, Druzhinina IS. 2008 - Fungal genus Hypocrea/Trichoderma: from barcodes to biodiversity. Journal of Zhejiang University Science B 9, 753-763. doi:10.1631/jzus.B0860015.

Kuhls K, Samuels GJ, Meyer W, Kubicek CP, Borner T. 1997 - Revision of Trichoderma sect. Longibrachiatum including related teleomorphs based on analysis of ribosomal DNA internal transcribed spacer sequences. Mycologia 89, 442-460.

Lopez E, Orduz S. 2003 - Metarhizium anisopliae and Trichoderma viride for control of nests of the fungus-growing ant, Atta cephalotes. Biological Control 27, 194-200.

Miyashira CH, Tanigushi DG, Gugliota AM, Santos DY. 2010 - Comparison of radial growth rate of the mutualistic fungus of Atta sexdens rubropilosa Forel in two culture media. Brazilian Journal of Microbiology 41, 506-511.

Napal GN, Buffa LM, Nolli LC, Defagó MT, Valladares GR, Carpinella MC, Ruiz G, Palacios SM. 2015 - Screening of native plants from central Argentina against the leaf-cutting ant Acromyrmex lundii (Guérin) and its symbiotic fungus. Industrial Crops Products 76, 275280.

Rojan PJ, Tyagi RD, Prévost D, Brar SK, Pouleur S, Surampalli RY. 2010 - Mycoparasitic Trichoderma viride as a biocontrol agent against Fusarium oxysporum f. sp. adzuki and Pythium arrhenomanes and as a growth promoter of soybean. Crop Protection 29, 14521459.

Saba H, Vibhash D, Manisha M, Prashant KS, Farhan H, Tauseef A. 2012 - Trichoderma - a promising plant growth stimulator and biocontrol agent. Mycosphere 3, 524-531.

Samuels GJ, Dodd SL, Lu BS, Petrini O, Schroers HJ, Druzhinina IS. 2006 - The Trichoderma koningii aggregate species. Studies in Mycology 56, 67-133. doi:10.3114/sim.2006.56.03

Samuels GJ, Ismaiel A, Bon MC, de Respinis S, Petrini O. 2010 - Petrini Trichoderma asperellum sensu lato consists of two cryptic species. Mycologia 102, 944-966.

Savazzini F, Longa CMO, Pertot I. 2009 - Impact of the biocontrol agent Trichoderma atroviride $\mathrm{SC} 1$ on soil microbial communities of a vineyard in northern Italy. Soil Biology and Biochemistry 41, 1457-1465.

Shali A, Ghasemi S, Ahmadian G, Ranjbar G, Dehestani A, Khalesi N, Motallebi E, Vahed M. 2010 - Bacillus pumilus SG2 chitinases induced and regulated by chitin, show inhibitory activity against Fusarium graminearum and Bipolaris sorokiniana. Phytoparasitica 38, 141-147. DOI 10.1007/s12600-009-0078-8.

Silva AC, Rodrigues A, Bacci MJ, Pagnocca FC, Bueno OC. 2006 - Susceptibility of the antcultivated fungus Leucoagaricus gongylophorus (Agaricales: Basidiomycota) towards microfungi. Mycopathologia 162, 115-119. DOI 10.1007/s11046-006-0037-6.

Steyaert JM, Ridgway HJ, Elad Y, Stewart A. 2003 - Genetic basis of mycoparasitism: A mechanism of biological control by species of Trichoderma. New Zealand Journal of Crop Horticultural Sciences 31, 281-291. DOI: http://dx.doi.org/10.1080/01140671.2003.9514263.

Susanto A, Sudharto OS, Purba RY. 2005 - Enhancing biological control of basal stem rot disease (Ganoderma boninense) in oil palm plantations. Mycopathologia 159, 153-157.

Vinale F, Sivasithamparam K, Ghisalberti EL, Marra R, Woo SL, Lorito M. 2008 - Trichoderma plant pathogen interactions. Soil Biology and Biochemistry 40, 1-10. http://dx.doi.org/10.1016/j.soilbio.2007.07.002.

White TJ, Bruns TD, Lee SB, Taylor JW. 1990 - Analysis of phylogenetic relationships by amplification and direct sequencing of ribosomal genes. In: Innis MA, Gelfand DH, Sninsky JJ, White TJ (eds) PCR Protocols. Academic Press, New York, pp. 315-22. 
Yao Y, Li Y, Chen Z, Zheng B, Zhang L, Niu B, Meng J, Li A, Zhang J, Wang Q. 2016 Biological Control of Potato Late Blight Using Isolates of Trichoderma. American Journal of Potato Research 93, 33-42. DOI 10.1007/s12230-015-9475-3.

Zeilinger S, Omann M. 2007 - Trichoderma Biocontrol: Signal Transduction Pathways Involved in Host Sensing and Mycoparasitism. Gene Regulation Systems and Biology 1, 227-234. 